\title{
Perceived Effect of Pubertal Developmental Body Changes on Academic Achievement Among Public Primary School Pupils in Sagana, Kirinyaga West Sub-County, Kenya
}

\author{
Susan Mwendwa Maina \\ Chuka University \\ Beatrice M. Mburugu \\ Chuka University
}

\begin{abstract}
Pupils in puberty face several challenges that affect their academic achievement. Academic achievement of pupils is also affected as boys and girls in puberty perform dismally. Puberty is a developmental stage for a human being characterized by increased changes in bodies of the young people. The body changes are manifested in emotional, physical and attitude changes that affect their academic performance. During the onset of this period, many young people attending school become affected posing potential risks to optimal academic achievement. The purpose of this study was to determine the perceived effect of pubertal developmental body changes on academic achievement among pupils in Sagana, Kirinyaga West Sub-County, Kenya. This study employed descriptive survey research design that comprises both quantitative and qualitative research procedures used for obtaining information from a large population. The researcher targeted 480 respondents comprising of twelve class teachers and 468 pupils in classes six and seven in six schools. Simple random sampling technique was used to obtain a sample size of 214 pupils from the target population of 468 pupils. The researcher also used purposive technique to obtain a sample of twelve class teachers. The researcher used questionnaires for teachers and pupils as well as achievement records for pupils to collect data. Validity of the instruments was confirmed through expert judgment from the Department of Education at Chuka University. The questionnaires and achievement tests were tested for reliability. Two schools were purposively selected for testing of the instruments using split half method. With a coefficient $(\alpha=0.81)$, the instruments were considered reliable for data analysis. Both qualitative and quantitative data were generated. Computer programme Statistical Package for Social Sciences Version 21 was used to analyse quantitative data that generated frequencies and percentages which were presented in Tables and Graphs. For qualitative data, content analysis was used to arrange data into themes. Findings indicating perceived effect of pubertal developmental body changes on academic achievement were established. Findings indicated that girls are affected more than boys in terms of academic performance. Also, the findings revealed that pubertal physical development changes are manifested differently in boys and girls with girls being affected most. This study concluded that while pubertal physical body changes occur in both boys and girls, the manifestation of the changes is more in girls than boys with boys exhibiting fewer effects. The study recommends that more strategies to help girls manage the pubertal changes should be devised as a means of improving their academic performance. The findings of this study will benefit pupils, teachers, NGOs, Ministry of Education and academicians.
\end{abstract}

Perceived Effect, Academic performance, pubertal body development, body changes, primary school pupil

DOI: $10.7176 / \mathrm{JEP} / 10-35-11$

Publication date: December $31^{\text {st }} 2019$

\section{Introduction}

Puberty is considered as a critical developmental stage for a human being since it is a stage characterized by tremendous changes in bodies of the young people (Mruk, 2013; Bucur, 2007; Zeigler-Hill, 2013). Also, girls are considered to be vulnerable than boys (Charbonneau, Mezulis, Hyde, 2009) with higher levels of adaptation than boys (Aunola, Stattin \& Nurmi, 2000). It is emerging that the physical body changes contribute to gender differences.

The challenges posed are different based on gender with girls experiencing more challenges than boys (UNICEF, 2008; Muchemi, 2007; Otieno, 2004; Mbatia, 2003; Njoroge, 2005; Pichi 2005; Charlayne, 2006). Effects of puberty on behavior of learners' cause misunderstanding of parents or teachers with the children in puberty stage. As the stage causes many social, emotional, physical and cognitive changes in these children, such changes may be detrimental to their learning process.

In Africa, many studies on puberty are focused more on girls than boys yet physical body changes are exhibited in both genders. For example, decline in academic achievement among girls has also been attributed to pubertal developmental body changes (Etsy, 2005, Chinyoka, 2014, Sowmyaa \& Archana, 2004; Kirimi, 2005). The onset of puberty among girls in Zimbabwe, Ghana and Malawi reduced their self-esteem due to lack of sanitary towels and lack of knowledge on use of sanitary towels that contributed to low academic achievement. 
Boys and girls in the puberty stage become very conscious of their body changes in respect to perceptions of people around them (Arcia, 2007; Bergquist, Bigbie, Groves, \& Richardson, 2004). However, how this is manifested in Sagana in Kirinyaga was yet to be established. In addition, reviewed studies have attempted to link puberty to behavior changes and self-esteem. Moreover, the studies do not fully elaborate the role of each physical change on self-esteem, academic performance and from the perspective of gender differences. For example, studies (Arcia, 2007; Bergquist, Bigbie, Groves et al., 2004) only describe the differences between boys and girls but not the extent to which such differences affect self-esteem and academic performance.

Mbatia, (2003) have also attempted to indicate that pubertal physical developmental changes are associated with academic achievement through many aspects. The extent to which pubertal physical developmental changes become favourable to boys and girls in puberty are likely to improve academic achievement or not. For example, during menstruation, girls without sanitary towels become absent from school (Mbatia, 2003; Muchemi, 2007; Akoth, 2004; Odhiambo, 2004). School absence implies interrupted learning that contributes to low academic achievement. Therefore, this paper intends to fill the existing gaps.

\subsection{Statement of the Problem}

Primary school pupils especially in classes six and seven have mainly recorded high rates of absenteeism while other and even drop out of school during the puberty stage. In Sagana area, primary school pupils face challenges associated with pubertal developmental body changes during the puberty stage thereby interrupting learning. The primary school pupils do not boldly express themselves during learning. In addition, the pupils sometimes record low performance yet they used to score highly. As the pupils are in puberty stage, the emerging question is whether the physical body changes contribute significantly to the academic achievement fluctuations. This study therefore sought to determine the perceived effect of pubertal developmental body changes on academic achievement among public primary school pupils in Sagana, Kirinyaga West Sub-County, Kenya.

\subsection{Purpose of the study}

The purpose of this paper was to determine the perceived effect of pubertal developmental body changes on academic achievement among pupils in Sagana, Kirinyaga West Sub-County, Kenya.

\subsection{Objective of the paper}

To examine the perceived effect of pubertal development stage on academic achievement among pupils in public primary schools in Sagana, Kirinyaga West Sub-County, Kenya.

\subsection{Puberty and Academic performance}

Puberty refers to the process of significant body changes that initiate sexual maturity in adolescents aged between 11 and 14 years (Mruk, 2013). The body changes are manifested in emotional, physical and attitude changes that affect behavior of the young people. In Kenya, puberty is also related to peer effect and academic achievement based on gender differences. Adolescents' relationships with peers' affect academic achievement in Vihiga County (Korir \& Kipkemboi, 2014). In Kiambu (Njoroge, 2005), Migori (Pichi, 2005), Northern Kenya (Mbatia, 2003; Muchemi, 2007) and Western Kenya (Akoth, 2004; Odhiambo, 2004) found that girls are affected by puberty when they begin their menstrual flows; lack of sanitary towels forces them to be absent from school. Even when in attendance, girls reportedly withdrew from school related activities both within and outside the class (Mbatia, 2003; Njoroge, 2005; Pichi 2005). This indicates how girls in puberty are affected than boys in same school conditions.

Pubertal physical developmental changes are associated with academic achievement through many aspects. The extent to which pubertal physical developmental changes become favourable to boys and girls in puberty are likely to improve academic achievement or not. Emotional, behavioural, social and pubertal developmental body changes have been associated with academic achievement of pupils in puberty (Combs, Clark, Moore, Onwuegbuzie, Edmonson, \& Slate, 2011; Beyens, Vandenbosch, \& Eggermont, in press; Mendle, Turkheimer \& Emery, 2010; Kedro, 2014; Fraser-Thill, 2014; UNICEF, 2008). As this study acknowledges the findings of these studies, such findings have not been demonstrated in Sagana. This study therefore sought to determine extent to which physical developmental changes affect academic achievement of pupils.

Low academic achievement is manifested when boys and girls in puberty perform dismally in school activities especially tests. Early puberty is an especially critical time for school achievement because it initiates a time when youth, particularly girls, can show marked declines in academic interests (Connolly, Hatchette \& Mc Master, 2008). Ganai and Mir (2013) define academic achievement as degree of competence in school activities measured by use of standardized tests. In their findings in Canada, Connolly, Hatchette and Mc Master (2008) observed that puberty affected pupils' social adjustments which limited their interactions at school and home. According to Mruk (2006), this reflects difference is self-evaluation resulting from sense of self-worth. However, pupils who showed beginning signs of pubertal development scored higher on the test of mathematics and this led to their conclusion 
that puberty may not be a risk factor for school achievement (Hatchette \& Mc Master, 2008). That is why this study sought to determine perceived effect of pubertal physical body changes on academic achievement in Sagana.

During menstruation, girls without sanitary towels become absent from school (Mbatia, 2003; Muchemi, 2007; Akoth, 2004; Odhiambo, 2004). School absence implies interrupted learning that contributes to low academic achievement (Mbatia, 2003; Muchemi, 2007; Akoth, 2004; Odhiambo, 2004). Njau (1997), reveals that the relationship between school attendance and girls' experience in reproductive events is more complex today than in the past due to the rising adolescent time being spent in school and inadequate guidance and counseling. was not applied hence making this research design suitable for this study.

\subsection{Theoritical Framework}

Two theories were used which included Albert Bandura's Social Learning Theory and Psychosocial Developmental Theory of by Erick Erickson

\subsection{Research Design}

Descriptive research design was used to collect opinions and perceptions of learners and teachers from respondents. Questionnaires and interviews were used in collecting data as well as records analysis.

\subsection{Population of Study}

Pupils in classes six and seven together with class teachers of classes six and seven were used as shown in Table 1.

Table 1

Distribution of Population by School

\begin{tabular}{lccccc}
\hline School & School population & \multicolumn{4}{c}{ Accessible Population } \\
& & Class 6 pupils & Class teachers & Class 7 pupils & Class teachers \\
\hline Muslim & 380 & 60 & 1 & 60 & 1 \\
Kahiro & 380 & 37 & 1 & 41 & 1 \\
Upper Sagana & 320 & 56 & 1 & 53 & 1 \\
Thangu & 146 & 19 & 1 & 11 & 1 \\
Lower Sagana & 500 & 50 & 1 & 43 & 1 \\
Gakandu & 200 & 19 & 1 & 19 & 1 \\
Total & 1926 & 241 & 6 & 227 & 6 \\
\hline
\end{tabular}

The target population of the study was 12 teachers and 468 pupils comprising of 241 pupils in class six and 227 pupils in class seven from six schools.

\subsection{Sampling Procedures and Sample Size}

The researcher used Kathuri and Pals (1993) to sample from a target population of 468 by use of simple random sampling technique to obtain 214 pupils. Simple random sampling is suitable for giving members of the population equal chance of participation. Purposive sampling was used to obtain the twelve class teachers who had achievement records of the pupils. The researcher obtained a sample of 226 respondents comprising of twelve teachers and 240 pupils in three public primary schools as distributed in Table 2.

Table 2

Distribution of Sample Size by Class

\begin{tabular}{lccc}
\hline \hline Category & Population & Sample frequency & Method of sampling \\
\hline Class six pupils & 241 & 107 & Simple random \\
Class seven pupils & 227 & 107 & Simple random \\
Class six and seven teachers & 12 & 12 & Purposive \\
Total & 480 & 226 & \\
\hline
\end{tabular}

\subsection{Instrumentation}

Questionnaires and achievement records were used to collect data from teachers and pupils.

\subsubsection{Questionnaires}

A class teacher questionnaire was developed to collect information on social learning of pupils in puberty in relation to physical body changes, gender differences, self-esteem and academic achievement. The questionnaire was used because the teachers could respond to the questions at their free time. The questionnaire also promoted privacy of the pupils which was one of the limiting factors to participation of the pupils in the study. Thus, it did not inconvenience their normal duties. The class teacher questionnaire contained questions three sections. The first section was used to collect demographic information of the teachers while second question was used to collect information on perceived effect of pubertal development changes on self-esteem and performance. The third section contained questions on pubertal developmental body changes and academic achievement. The fourth 
section contained questions on gender differences in relation to pubertal physical changes, self-esteem and academic performance.

Questionnaire for pupils comprising of structured and unstructured questions was administered to pupils to obtain detailed information about their demographic background, behavior, feelings and response to the questions asked as illustrated in Appendix C.

\subsubsection{Achievement Records}

Achievement records were used to obtain achievement of learners. Records of the pupils of their average achievement in three consecutive tests were collected. Level of participation in co-curriculum and other activities were recorded. The overall achievement of the pupils was calculated by taking average of the performance in tests and level of participation.

\subsection{Reliability}

Reliability is a measure of how consistent the results from instruments are. During construction of evaluation instruments, reliability is increased by precise identification of data required and repeated review of instruments by knowledgeable evaluators and field test on appropriate population (Mulusa, 1996). To estimate reliability of instruments, testing of the instruments in schools which were not factored in real data collection was done. Two schools were purposively selected for testing of the reliability of instruments using split half method. According to Mugenda and Mugenda (2008), a reliability coefficient of above 0.7 is suitable for the study. The instrument yielded a reliability coefficient of $\alpha=0.81$ which was considered reliable and accepted for data collection.

\subsection{Validity}

Validity of research instruments involves the ability of an instrument to test or measure what is intended to measure (Kombo \& Tromp, 2006). Expert judgment from the Department of Education at Chuka University was used to ascertain content of the instruments. The researcher verified the outcome of the instruments based on the objectives of the study. In addition, face and construct validity were improved by the researcher during the piloting phase. The improvement included eliminating irrelevant questions. Also, some questions were rephrased to eliminate ambiguities.

\section{Results}

\subsection{Results and discussions}

4.1 Perception of Pupils about Physical Pubertal Body Changes and Academic Performance

Pupils provided the following responses about pubertal developmental body changes and academic performance as illustrated in Table 3 .

Table 3

Perception of Pupils about Physical Pubertal Body Changes and Academic Performance

\begin{tabular}{lc}
\hline \hline Statement & Mean \\
\hline Girls and boys with increased weight have high levels of class participation and attendance & 1.97 \\
Girls with enlarged breasts have high levels of class participation and attendance & 2.3 \\
Boys with broken voice have high levels of class participation and attendance & 2.3 \\
Girls have high level of class participation and attendance during menstruation. & 2.2 \\
Boys and girls with pimples have high level of class participation and attendance & 1.7 \\
Overall & 1.75
\end{tabular}

Scale: $1=$ Strongly Disagree; $2=$ Disagree; $3=$ Neutral; $4=$ Agree; $5=$ Strongly Agree

Findings in Table 3 indicate that most of the pupils (mean of 1.97) strongly disagree that weight increase has improved their class attendance and participation. The findings also indicate that most girls (mean of 2.3) disagree that their breast enlargement has improved class attendance and participation. With a mean of 2.3, most boys disagree that breaking of their voices has improved their class participation and attendance. Also, with a mean of 2.2 , most girls disagree that menstruation has improved class participation and attendance. The findings also reveal that most pupils (mean of 1.7) strongly disagree that occurrence of pimples has improved class participation and attendance. With an overall mean of 1.75 , the findings indicate that most pupils strongly disagree that physical developmental changes improve their class attendance and participation. The finding agrees with Mruk (2006) that found that beginning signs of pubertal development, pupil scored higher on the test of mathematics and this led to their conclusion that puberty may not be a risk factor for school achievement.

\subsection{Perception of Teachers on Pubertal Development Body Changes and Academic Performance}

Teachers provided the following responses on pubertal development body changes and academic performance as illustrated in Table 4. 
Table 4

Perception of Teachers on Pubertal Development Body Changes and Academic Performance

\begin{tabular}{lc}
\hline \hline Statement & Mean \\
\hline Boys with increased weight have high level of academic achievement. & 1.92 \\
Girls with increased weight have high level of academic achievement. & 1.50 \\
Girls with enlarged breasts have high level of academic achievement. & 1.67 \\
Boys with broken voice have high level of academic achievement. & 1.50 \\
Girls' academic achievement is most affected during menstruation. & 4.50 \\
Boys with pimples have high level of academic achievement. & 1.50 \\
Girls with pimples have high level of academic achievement. & 1.58 \\
Overall & 2.02
\end{tabular}

Scale: 1=Strongly Disagree; 2=Disagree; 3=Neutral; 4=Agree; 5=Strongly Agree

Findings on perceptions of teachers about academic performance and pubertal development body changes as illustrated in Table 13 indicate that weight increase, breast enlargement, breaking of voice, emergence of pimples in both boys and girls do not improve academic performance of boys and girls as observed in mean of 1.92, 1.50, $1.67,1.50,1.50$ and 1.58 respectively. Menstruation in girls significantly (mean of 4.50) affects girls' academic achievement. These findings are confirmed by an overall mean of 2.02 where physical body changes do not improve academic achievement of the pupils

Findings in 3 and 4 indicated that pubertal body changes affect academic performance of pupils in puberty. The physical body changes were manifested more in girls (weight increase, breast enlargement, hip enlargement, emergence of pimples and menstruation) yet they performed marginally above boys who have few pubertal physical body changes (voice breaking, weigh increase and enlargement of shoulders). The findings on performance of the pupils indicate that boys are not significantly affected by pubertal physical changes hence no significant change in academic performance. Class participation, concentration and class attendance in girls was affected than boys yet performance was below that of girls especially during menstruation.

These findings concur with Etsy (2005), Chinyoka (2014), Sowmyaa and Archana (2004) and Kirimi (2005) findings, that decline in academic achievement among girls has also been attributed to pubertal developmental body changes. The findings are in line with Njoroge (2005), Pichi (2005), Mbatia (2003), Muchemi (2007), Akoth (2004) and Odhiambo (2004) findings that girls are affected by puberty when they begin their menstrual flows; lack of sanitary towels forces them to be absent from school. This study indicates that though the girls performed significantly better than boys, their performance could have been better if they could not have been limited by low self-esteem.

\subsection{Conclusion}

Girls' academic performance from perceptions and records (Girls=Mean 247, Boys $=267$ respectively) is therefore affected negatively by Pubertal physical development changes than that of boys. Boys are less affected by pubertal physical changes than girls from respondent's perceptions. The society also perceives puberty in girls as developmental changes that should make the girls not equal to boys as boys are praised during puberty than girls despite girls performing better than boys. Therefore, this study concludes that pubertal development body changes affect academic achievement among girls than boys in Sagana, Kirinyaga West Sub-County.

\subsection{Recommendations}

School management and teachers should devise strategies and activities that could support pupils especially girls to manage pubertal challenges hence improving their academic achievement.

School management and teachers should liaise with community members in developing initiatives aimed at reducing stereotypes around puberty especially in girls can be done on academic clinic days, sports days and festivals.

\section{References}

Akoth, S. (2004). Problems Faced by Primary School Head Teachers in Implementing Free Primary Education in Kisumu Municipality; Kenya. Unpublished Master of Education Project. Department of Educational Administration, Planning and Curriculum Development. Kenyatta University. Nairobi.

Aunola, K., Stattin, H., \& Nurmi, J. (2000). Adolescents' Achievement Strategies, School Adjustment, and Externalizing and Internalizing Problem Behaviors. J Youth Adolescence 29(3): 289-306.

Boadu, E., (2000). Gender Disparities in Education, Health, and Labour Force Participation in Ghana. Accra: University of Ghana

Bronfenbrenner, U. (2008). Ecology of Human Development. Cambridge MA: Harvard University Press.

Byrnes, V., \& Ruby, A. (2007). Comparing Achievement between K-8 and Middle schools: A Large-Scale Empirical Study. American Journal of Education, 114, 101135. 
Cameron, S. (2012). Education, Urban Poverty and Migration: Evidence from Bangladesh and Vietnam. Working Paper 2012- 2015. UNICEF Office of Research, Florence.

Camfed, C. (1994). Supporting Girls Education in Zimbabwe. Harare. The Cambridge Female Education Trust.

Chinyoka, K., \& Naidu, N. (2013). Perceived effect of Home-Based Factors on the Academic Achievement of Girl Learners from Poverty Stricken Families: A Case of Zimbabwe, Mediterranean Journal of Social Sciences, $5(6)$.

Combs, J., Clark, D., \& Moore, G., (2011). Academic Achievement for Fifth-Grade Students in Elementary and Intermediate School Settings: Grade Span Configurations, Current Issues in Education, 14(1).

Flannery, D., Rowe, D., Gulley, B. (1993). Perceived Effect of Pubertal Status, Timing, and Age on Adolescent Sexual Experience and Delinquency. $J$ Adolescence Res, 8,21- 40.

Foreyt, J., Poston, W., Winebarger, A., McGavin, J. (1998). Anorexia Nervosa and Bulimia Nervosa. In: Mash EJ, Barkley RA, editors. Treatment of Childhood Disorders. New York: Guildford Press.

Forrest, M. (2013). Health and School. Journal of Adolescent Health, 3(2): 345-352.

Fournet, D., Wilson, K., \& Wallander, J. (1998). Growing or Just Getting Along? Technical and Adaptive Competence in Coping among Adolescents. Child Dev 69(4): 1129-1144.

Franky, D., \& Chamundeswari, S. (2014). Psycho-social Correlates of Academic Achievement of Students, International Journal of Current Research and Academic Review, 2(2), 148-158

Goodson, P., McCormick, D., \& Evans, A. (2001). Searching for Sexually Explicit Materials on the Internet: An Exploratory Study of College Students' Behavior and Attitudes. Archives of Sexual Behavior, 30, 101-118.

Gordon, Catharine M., Laufer. M. (2005). Chapter 4: Physiology of Puberty', in Emans, S., Goldstein D, Laufer, M, eds.: Pediatric and Adolescent Gynecology, $5^{\text {th }}$ ed., Philadelphia: Lippincott, Williams \& Wilkins.

Graber, J., Brooks-Gunn, J., \& Warren, M. (1999). The Vulnerable Transition: Puberty and the Development of Eating Pathology and Negative Mood. Women's Health Issues 9:107-114.

Graber, J., Lewinsohn, P., Seeley, J., \& Brooks-Gunn, J. (1997). Is Psychopathology Associated with the Timing of Pubertal Development? Journal of the American Academy of Child and Adolescent Psychiatry 36(12):1768-1776.

Graber, J., Seeley, J., Brooks-Gunn, J., \& Lewinsohn, P. (2004). Is Pubertal Timing Associated with Psychopathology in Young Adulthood? Journal of the American Academy of Child and Adolescent Psychiatry 43(6):718-726.

Hayatbakhsh, M., Najman, J., McGee, T., Bor, W., \& O'Callaghan, M. (2012). Early Pubertal Maturation in the Prediction of Early Adult Substance Use: A Prospective Study. Addiction, 104(1), 59-66.

Haynie, D. (2003). Contexts of Risk? Explaining the Link between Girls' Pubertal Development and their Delinquency Involvement. Social Forces 82:355-397.

Hayward, C., Killen, J., \& Wilson, D. (1997). Psychiatric Risk Associated with Early Puberty in Adolescent Girls. Journal of the American Academy of Child and Adolescent Psychiatry 36(2):255-262.

Jacobson, L., \& Burdsal, C., (2012). Academic Achievement in Middle School: Friendship Effects, Global Journal of Community Psychology Practice, 2(3),1-12.

Jewitt, S., \& Ryley, H., (2014). It's a Girl Thing: Menstruation, School Attendance, Spatial Mobility and Wider Gender Inequalities in Kenya. Geoforum 56 (2014) 137-147.

Kaltiala-Heino, R., Marttunen, M., Rantanen, P., \& Rimpela, M. (2003). Early Puberty is Associated with Mental Health Problems in Middle Adolescence. Social Science and Medicine 57:1055-1064.

Kedro, M. (2009). The Impact of Puberty \& Its effect on School Performance. [online] Accessed 24 August 2015 at: http://oureverydaylife.com/impact-puberty-its affect-school-performance-35653.html.

Kiminyo, D. (1995). Child Development. $2^{\text {nd }}$ edition. Educational and Research Publishers ltd. Nairobi Kenya Literature Bureau.

Kirimi, M (2005). Toilet Shortage and Poor Hygiene Hamper Kenya's Free Education. Report on Assessment of Sanitary Facilities in Kenya's Public Primary Schools April 2004 to February 2005- prepared for the Network for Water and Sanitation International

Kling K, Hyde J, Showers C, Buswell B (1999). Gender Differences in Self-esteem: a Meta-Analysis. Psychol Bull 125(4): 470-500.

Korir D., \& Kipkemboi, F., (2014). The Perceived effect of School Environment and Peer Effects on Students' Academic Achievement in Vihiga County, Kenya, Journal of Education and Practice, 5(11), 2014.

Muchemi, L. (2007). A Study of School Factors Contribution to Primary School Girls Drop out in Rumuruti Division, Laikipia District, Kenya. Master of Education Thesis. Department of Educational Psychology. Kenyatta University. Nairobi.

Mugenda, O., \& Mugenda, A. (2008). Research Methods: Quantitative and Qualitative Approaches. Nairobi: Acts Press.

Njoroge, J. (2005). An Investigation into the Causes of Drop out amongst Girls in Public Primary Schools in Githunguri Division of Kiambu District. Master of Education Thesis. Kenyatta University. Nairobi. 
Pichi, L. (2005). Factors Contributing to Declining Numbers of Girls in Public Primary Schools in Nyatike division, Migori District. Master of Education Project. Department of Educational Foundations. Kenyatta University. Nairobi

Rieder, J., \& Coupey, S. (1999). Update on Pubertal Development. Current Opinion in Obstetrics and Gynecology 11:457-462.Roseth,

UNICEF (2008). Girls; Education Campaigns. [Online]. Accessed September 16, 2015 at: http://www.unicef.org/education/campaign.html.

Weiss, C., \& Kipnes, L. (2006). Reexamining Middle School Effects: A Comparison of Middle Grade Students in Middle Schools and K-8 Schools. American Journal of Education, 112, 239-272.

Wentzel, K., McNamara Barry, C., \& Caldwell, K. (2004). Friendships in Middle School: Effects on Motivation and School Adjustment. Journal of Educational Psychology, 96(2), 195-203.

Yara, P., \& Ndirangu, J. (2012). Determinants of Female Students' Achievement in Primary Schools in Loitokitok District of Rift Valley Province, Kenya. International Journal of Business and Social Science, 3 (12). 